\title{
Đi tìm lời giải cho bài toán ô nhiễm rác thải sinh hoạt nông thôn ở Việt Nam
}

\author{
Đỗ Thùy Trang, Ngô Thị Ngọc Bích \\ Đại học Quốc gia Hà Nội
}

Hà Nội, ngày 28 tháng 12 năm 2021

\section{Preprint DOI: 10.31219/osf.io/23d98}

Ô nhiễm môi trường không chỉ ảnh hưởng đến sức khỏe, mỹ quan mà còn tác động đến kinh tế xã hội, văn hóa. Vấn đề ô nhiễm môi trường đang nhận được sự quan tâm của người dân, nhà khoa học, nhà quản lý môi trường và cộng đồng dân cư (Nguyen \& Vuong, 2021; Uyen et al., 2021; Van Khuc et al., 2020; Q. Vuong et al., 2021). Trong ô nhiễm môi trường, ô nhiễm rác thải sinh hoạt ở nông thôn đang gây nhức nhối ở Việt Nam.

Trước khi đi tìm lời giải cho bài toán ô nhiễm môi trường nêu trên, việc tìm hiểu nguyên nhân là quan trọng đầu tiên. Có nhiều nguyên nhân được tổng hợp trong đó bao gồm: Gia tăng dân số, phát triển đô thị hóa nông thôn, thay đổi lối sống, tiêu dùng cá nhân tăng. Điều này đã làm gia tăng về khối lượng rác thải sinh hoạt và hậu quả nặng nề là sự ô nhiễm rác thải sinh hoạt nông thôn (Astane \& Hajilo, 2017). Đối với một quốc gia đang phát triển như Việt Nam, vấn đề rác thải sinh hoạt nông thôn thực sự là nút thắt cần được gỡ bỏ.

Cùng với quá trình đô thị hóa nông thôn, người dân ngày càng có xu hướng di cư đến khu vực nông thôn định cư. Thực tế, Việt Nam có khoảng hơn 60 triệu dân sống ở vùng nông thôn, chiếm hơn $73 \%$ dân số cả nước. Dân cư tăng lên dẫn đến nhiều vấn đề về rác thải sinh hoạt và xử lý rác thải sinh hoạt. Theo báo Công thương, trung bình mỗi năm ở khu vực nông thôn phát sinh trên 13 triệu tấn rác thải sinh hoạt, nhưng tỷ lệ thu gom chỉ đạt $40 \%$, tỷ lệ tái chế chưa đạt đến $4 \%$, còn những rác thải chưa được xử 
lý thì xả trực tiếp ra môi trường (Uyên, 2021). Bên cạnh đó, các biện pháp về xử lý rác thải tại gia, tại địa phương chưa được quy hoạch rõ ràng, gây ra tình trạng tất cả các loại rác đều đổ chung một chỗ, ảnh hưởng đến công tác xử lý. Vì vậy, công tác thu gom, xử lý rác thải sinh hoạt ở khu vực nông thôn cần được nâng cao cải thiện.

Sự ô nhiễm rác thải sinh hoạt tại từng vùng nông thôn Việt Nam bị tác động bởi một số yếu tố trọng điểm (Astane \& Hajilo, 2017; Han et al., 2018) bao gồm:

Yếu tố kinh tế, vấn đề đô thị hóa nông thôn, xây dựng nông thôn mới hiện đang là mục tiêu mà hầu hết các địa phương tại Việt Nam hướng tới, kéo theo sự thay đổi cơ cấu kinh tế, hình thức sản xuất kinh doanh và sự tập trung mạnh mẽ của các khu công nghiệp mới. Tuy nhiên, song song với đó là sự tăng lên về khối lượng của rác thải sinh hoạt nông thôn.

Yếu tố văn hóa môi trường có ảnh hưởng đến hiện trạng ô nhiễm rác thải hiện nay. Yếu tố văn hóa môi trường ở đây bao gồm nhận thức con người, yếu tố này tồn tại thông qua suy nghĩ chủ quan về tác động của các loại rác thải khó phân hủy và hành động thực tế là sự không phân loại rác thải hay hành động vứt rác bừa bãi tại các điểm tập kết rác tự phát, vứt rác bừa bãi ra kênh ngòi, ao, rạch... Thời gian qua Giáo sư Vương Quân Hoàng và cộng sự đã tập trung nghiên cứu cụm tư tưởng văn hóa môi trường (Q.H. Vuong, 2021; Q.-H. Vuong et al., 2019; Q. H. Vuong et al., 2021) bao gồm có nguyên lý bán dẫn (Q. H. Vuong, 2021). Việc tuyên bố rõ ràng rằng không thể đánh đổi giá trị môi trường với giá tri kinh tế là gợi ý đột phá để con người tiêu dùng tiết kiệm tài nguyên, bảo vệ môi trường và tính toán lợi ích phải tính cả giá trị môi trường.

Hệ thống quản lý và xử lý rác thải sinh hoạt. Trên thực tế, tại nông thôn Việt Nam vẫn còn tồn tại phương thức quản lý rác thải thiếu quy hoạch thông qua hàng loạt bãi tập kết rác tự phát, hoạt động phân loại tại nguồn chưa được đẩy mạnh và phương thức xử lý rác thải chủ yếu là chôn lấp với kỹ thuật đơn giản (Dung, 2017).

Sự thiếu quan tâm của các cấp chính quyền. Thực tế cho thấy bộ máy chính quyền trong công tác quản lý, xử lý rác thải tại mỗi địa phương chưa được đồng bộ ("Nguyên Nhân Của Các Tồn Tại Trong Công Tác Bảo vệ Môi Trường,” 2020). Bên cạnh đó, điều kiện vật chất và cam kết trong công tác thực hiện đẩy lùi ô nhiễm rác thải sinh hoạt còn trở ngại và chậm trễ. Nguồn nhân lực ít và yếu kém càng làm cho vấn đề thêm trầm trọng hơn. 
Vấn đề ô nhiễm rác thải sinh hoạt nông thôn đã tác động đến môi trường sống và cuộc sống của con người (Thị Minh Hạnh, 2014). Với số lượng rác thải tăng lên theo cấp số nhân, môi trường đất, nước, không khí tại nông thôn đều đang trong mức báo động. Điều này đã tác động trực tiếp đến đời sống sinh hoạt của con người khi chất lượng nguồn nước, không khí không được đảm bảo. Bên cạnh đó, việc sống trong một mùi hôi thối của rác, một bầu không khí đầy khói bụi còn gia tăng sự khó chịu và là một trong những tác nhân cho việc xuất hiện các bệnh lý về phổi, đường hô hấp, các bệnh về ruột...

Tóm lại, vấn đề ô nhiễm rác thải sinh hoạt nông thôn là chủ đề được quan tâm và đáng lưu ý hiện nay. Nhà nước và các nhà chức trách tại các địa phương đã có những biện pháp để giải quyết như khuyến khích người dân sử dụng rác thải hữu cơ làm phân bón, phân chia rác hữu cơ, rác tái chế tại gia để dễ dàng cho công tác xử lý...nhưng chưa thực sự hiệu quả. Sử dụng cách tiếp cận văn hóa (văn hóa môi trường) (Khuc, 2021) để tăng cường nhận thức về việc xử lý rác thải sinh hoạt, tích cực quan tâm đến việc xử lý rác của địa phương là rất quan trọng trong thời gian tới. Song song với đó, đầu tư nâng cấp cơ sở vật chất hạ tầng xử lý rác thải bằng hình thức công-tư (nhà nước và nhân dân cùng làm). Thu hút và tạo điều kiện để các thành phần tư nhân tham gia vào lĩnh vực xử lý môi trường. Mặc dù vẫn còn những tranh luận liên quan đến chi phí - lợi ích cho lĩnh vực khoa học giáo dục (Q. H. Vuong, 2018), nhưng nhà nước cần đặc biệt quan tâm đến hệ thống đào tạo giáo dục cho thế hệ trẻ, thanh niên về môi trường, bảo vệ môi trường (Q. Vuong, 2020). Hình thành hệ sinh thái giải pháp sẽ góp phần giải quyết hiệu quả thực trạng môi trường nói chung và rác thải ở nông thôn hiện nay.

\section{Tài liệu tham khảo}

Astane, A. R. D., \& Hajilo, M. (2017). Factors affecting the rural domestic waste generation. Global Journal of Environmental Science and Management, 3(4), 417-426. https://doi.org/10.22034/gjesm.2017.03.04.007

Dung, P. D. (2017). Thực trạng rác thải sinh hoạt tại Việt Nam. VietEnvi. https://congtyxulynuoc.com/thuc-trang-rac-thai-sinh-hoat-tai-viet-nam/

Han, Z., Liu, Y., Zhong, M., Shi, G., Li, Q., Zeng, D., Zhang, Y., Fei, Y., \& Xie, Y. (2018). Influencing factors of domestic waste characteristics in rural areas of developing countries. In Waste Management (Vol. 72, pp. 45-54). https://doi.org/10.1016/j.wasman.2017.11.039

Khuc, Q. Van. (2021). Environmental culture thoughts to make a better world for our nature and children. OSF Preprints. https://doi.org/10.31219/osf.io/g5zex 
Nguyen, M.-H., \& Vuong, Q.-H. (2021). Evaluation of the Aichi Biodiversity Targets: the international collaboration trilemma in interdisciplinary research. Pacific Conservation Biology. https://doi.org/10.1071/pc21026

Nguyên nhân của các tồn tại trong công tác bảo vệ môi trường. (2020). Tổng Cục Môi Truoòng. http://ceid.gov.vn/nguyen-nhan-cua-cac-ton-tai-han-che-trong-cong-tac-bao-vemoi-truong/

Thị Minh Hạnh, P. T. T. (2014). Chương 4 Tác động của ô nhiễm môi trường nông thôn. In Báo cáo môi trường quốc gia 2014.

Uyen, D. T. H., Linh, N. D., \& Hien, N. T. T. (2021). Vấn đề rác thải nhựa ở Việt Nam. OSF Preprints. https://doi.org/10.31219/osf.io/76ku4

Uyên, N. M. (2021). Rác thải nông thôn- bài toán khó cần lời giải cu thể. Người Đưa Tin. https://www.nguoiduatin.vn/rac-thai-nong-thon-bai-toan-kho-can-loi-giai-cu-thea535233.html

Van Khuc, Q., Phu, T. V., \& Luu, P. (2020). Dataset on the Hanoian suburbanites' perception and mitigation strategies towards air pollution. Data in Brief, 33, 106414. https://doi.org/10.1016/j.dib.2020.106414

Vuong, Q.-H. (2021). Western monopoly of climate science is creating an eco-deficit culture. Economy, Land \& Climate Insight, 1-9.

Vuong, Q.-H., Bui, Q.-K., La, V.-P., Vuong, T.-T., Ho, M.-T., Nguyen, H.-K. T., Nguyen, H.-N., Nghiem, K.-C. P., \& Ho, M.-T. (2019). Cultural evolution in Vietnam's early 20th century: A Bayesian networks analysis of Hanoi Franco-Chinese house designs. Social Sciences \& Humanities Open, 1(1), 100001. https://doi.org/10.1016/j.ssaho.2019.100001

Vuong, Q. (2020). From children's literature to sustainability science, and young scientists for a more sustainable Earth. Journal of Sustainability Education, 24(December).

Vuong, Q. H. (2018). The (ir)rational consideration of the cost of science in transition economies. Nature Human Behaviour, 2(1), 5. https://doi.org/10.1038/s41562-0170281-4

Vuong, Q. H. (2021). The semiconducting principle of monetary and environmental values exchange. Economics and Business Letters, 10(3), 284-290. https://doi.org/10.17811/ebl.10.3.2021.284-290

Vuong, Q. H., Ho, M. T., Nguyen, M. H., Pham, T. H., Vuong, T. T., Khuc, Q., Ho, H. A., \& La, V. P. (2021). On the environment-destructive probabilistic trends: A perceptual and behavioral study on video game players. Technology in Society, 65(January), 101530. https://doi.org/10.1016/j.techsoc.2021.101530

Vuong, Q., Phu, T. V., Le, T. T., \& Khuc, Q. Van. (2021). Exploring Inner-City Residents' and Foreigners' Commitment to Improving Air Pollution: Evidence from a Field Survey in Hanoi, Vietnam. Data, 6(39). https://doi.org/10.3390/data6040039 